\title{
Primary HIV infection: a medical and public health emergency requiring rapid specialist management
}

\author{
Authors: Sarah Fidler ${ }^{\mathrm{A}}$ and Julie Fox ${ }^{\mathrm{B}}$
}

Primary HIV infection (PHI) refers to the first six months following HIV acquisition and represents a unique opportunity for expedited diagnosis, and consideration of rapid antiretroviral therapy (ART) initiation to improve immune function, reduce the size of the viral reservoir and limit the risk of onward viral transmission. Failure to diagnose and rapidly treat individuals with PHI has significant individual and public health implications. The Strategic Timing of AntiRetroviral Treatment trial recently identified a clinical benefit of immediate ART over deferral of treatment according to CD4 count threshold, and has led to rapid changes in World Health Organization and specialist national guidelines. For all individuals living with HIV, the offer of immediate therapy irrespective of CD4 count is now recommended. This paper summarises the presentation and management of $\mathrm{PHI}$, incorporating current research and guideline changes and discusses the role of PHI in onward transmission.

\section{HIV in the UK}

At the end of 2014 there were an estimated 103,700 individuals living with HIV; ${ }^{1} 6,151$ individuals were newly diagnosed HIV positive with rates highest in men who have sex with men (MSM) ( $\mathrm{n}=3,360)$. Of new diagnoses, $22 \%$ had proven recent infection and this was highest among gay and bisexual men. This increase in HIV incidence has occurred despite increased HIV testing to reduce those undiagnosed and effective use of antiretroviral therapy (ART), which substantially reduces infectiousness. ${ }^{2-4}$ The risk of onward transmission correlates with plasma viral load. ${ }^{5}$ Individuals at the earliest stage of infection, referred to as primary HIV infection (PHI) are particularly infectious as they often have extremely high viral load levels, the transmitted virus itself has characteristics that enhance the spread of infection and concomitant sexually transmitted infection (STI) may increase HIV infectiousness. ${ }^{6}$ The majority of HIV transmissions occur from individuals who are unaware of their diagnosis or not on suppressive ART. Therefore correct diagnosis and linkage to care and treatment are critical to reducing HIV incidence in the UK. ${ }^{7}$

Authors: ${ }^{A}$ reader and consultant in HIV medicine, Imperial College London, London, UK; ${ }^{\mathrm{B}}$ consultant HIV physician, Guys and St Thomas' NHS Trust, London, UK

\section{Diagnosis of PHI}

PHI represents the initial six months following HIV acquisition. This stage of infection is associated with a high-level plasma viraemia which is subsequently limited by host immune responses which confer symptomatic and partial immunological recovery for the majority of individuals. ${ }^{8}$ In the absence of ART a gradual decline in peripheral CD4 T cells is observed; on average between $50-70$ cells/year. ${ }^{9}$ Viral dissemination and the establishment of a viral reservoir throughout the body occurs rapidly after acquisition ${ }^{9}$ and is the reason why ART cannot cure HIV infection. ${ }^{10,11}$ Despite years of successful suppressive ART a latent pool of HIV-infected cells is thought to be the source of viral recrudescence on stopping therapy. ${ }^{11}$

\section{Challenges of PHI diagnosis}

The standard test for HIV infection is an HIV-specific antibody, which can be performed as a point-of-care finger prick test or a laboratory fourth generation combination assay detecting the presence of HIV antibody and or viral gag protein (p24). ${ }^{12}$ Individuals presenting very soon after HIV acquisition, with acute infection, may present prior to the production of detectable levels of HIV-specific antibodies, using routine point-of-care or laboratory assays. In these situations, confirmation of an HIV diagnosis can be made from venous blood samples sent to a virology laboratory where the presence of viral proteins (p24) or viral HIV DNA or RNA can be made. ${ }^{13}$ Laboratory third generation tests do not detect viral gag protein (p24) and therefore are less able to detect early infection prior to the development of detectable levels of HIV antibody. The lack of detectable antibodies in the initial stages of infection makes this a difficult diagnosis to make using current standard tests. The window period (ie the time between transmission and production of HIV antibodies when an HIV enzyme-linked immunosorbent assay result may be falsely negative) for a third generation antibody test is 21 days and for a fourth generation combination assay (ie the presence of p24 antigen in the absence of antibody) is 14 days after infection. ${ }^{14}$ The recent HIV test algorithm (RITA), carried out by Public Health England, can also identify recent infection providing the clinic is part of the surveillance network. ${ }^{15}$ Table 1 summarises the different tests available to diagnose HIV infection.

The majority of symptoms associated with PHI are nonspecific $^{15}$ and hence often misdiagnosed or overlooked. Table 2 highlights some of the symptoms, signs and recommended tests that can be associated with PHI. In view of the increased 


\begin{tabular}{|c|c|c|}
\hline $\begin{array}{l}\text { Diagnostic } \\
\text { test }\end{array}$ & Diagnostic method & $\begin{array}{l}\text { Time from infection to } \\
\text { detection }\end{array}$ \\
\hline $\begin{array}{l}\text { HIV antibody } \\
\text { test }\end{array}$ & $\begin{array}{l}\text { Venous blood; POC finger } \\
\text { prick test; oral swab test; } \\
\text { self-testing }\end{array}$ & $\begin{array}{l}21 \text { days (discordance } \\
\text { in POC results strongly } \\
\text { suggests } \mathrm{PIH} \text { ) }\end{array}$ \\
\hline $\begin{array}{l}\text { p24 antigen } \\
\text { test }\end{array}$ & $\begin{array}{l}\text { Venous blood sample } \\
\text { fourth generation combo- } \\
\text { antigen-antibody test }\end{array}$ & 14 days \\
\hline RITA & Venous blood PHE & $\begin{array}{l}\text { Up to } 16 \text { weeks from } \\
\text { estimated date of infection }\end{array}$ \\
\hline $\begin{array}{l}\text { HIV RNA or } \\
\text { DNA }\end{array}$ & Venous blood PCR & 7 days of infection \\
\hline
\end{tabular}

risk of missed diagnoses of acute HIV infection, the presence of certain indicator diseases should trigger the offer of HIV testing, ${ }^{16,17}$ for individuals presenting with signs or symptoms of Epstein-Barr virus, cytomegalovirus, secondary syphilis, tuberculosis and bacterial pneumonia. As a result of the challenges with current technology at accurately diagnosing acute HIV infection, encouraging both access and increasing the frequency of HIV testing among those at highest risk are key to improving timely identification of PHI. Increasing HIV testing outside of genitourinary medicine ${ }^{18}$ and the recent legalisation of self testing ${ }^{19}$ are anticipated to improve coverage.

\section{Initial management and counselling}

Heightened awareness of PHI with urgent referral for ART discussion has the potential to enhance clinical outcome and reduce the risk of onward viral transmission.

Initial counselling must be provided, as well as urgent contact tracing to enable urgent HIV testing of partners and post-exposure prophylaxis (PEP), ${ }^{20}$ if exposure occurred within the preceding 72 hours. Rarely PHI can present with opportunistic infections or severe neurological involvement requiring urgent management, otherwise, PHI tend to be mild, temporary and self-limiting. Interventions to consider at this time include ART, screening and treatment of concomitant STI, and the promotion of immediate changes in sexual behaviour. ${ }^{21}$ These include consistent condom use, limiting drug and alcohol intake (which may impair the ability

\section{Key points}

Identification of primary HIV in any medical setting remains a priority.

Encouragement of frequent testing across all settings.

Rapid referral to an HIV specialist is essential.

There is a time window of opportunity in ART within which immediate ART initiation confers enhanced clinical benefit.

KEYWORDS: Acute HIV infection, immediate clinical HIV management, antiretroviral therapy

to negotiate safe sex), and the incorporation of alternative sexual practices that do not involve the exchange of body fluids.

Keeping individuals engaged in care and not passing HIV on during this period of hyper-infectiousness is of paramount importance. Initial counselling is essential as well as rapid contact tracing to enable urgent HIV testing and provision of PEP (if exposure occurred within preceding the 72 hours) to partners.

\section{Antiretroviral treatment}

The recent change in UK treatment guidelines ${ }^{22}$ recommending initiation of ART for all people living with HIV irrespective of CD4 count is similarly pertinent to those diagnosed with $\mathrm{PHI}$, and reflects new evidence from the Strategic Timing of AntiRetroviral Treatment ${ }^{23}$ trial. The trial identified a significant reduction in the combined endpoint of AIDS events, serious non-AIDS events and death for immediate initiation of ART for all people living with HIV.

PHI differs from chronic infection as there are reasons to fast track individuals with PHI for immediate ART initiation, whereas those with asymptomatic chronic infection and CD4 counts $>350$ cells $/ \mathrm{cm}^{3}$ do not have the same level of urgency to start therapy.

> Preservation of CD4 T lymphocytes (total CD4 counts and ratio of CD4:8 T cells) correlates with all-cause mortality and recovery is directly related to the timing of ART initiation. ${ }^{24-26}$

$>$ Reduction in the enhanced risk of onward transmission of HIV associated with PHI. ${ }^{27-32}$

> Limitation in the size of latent pool of HIV-infected cells; the viral reservoir, ${ }^{33,35}$ which has been associated with

\section{Table 2. Symptoms, signs and recommended diagnostic tests associated with PHI.}

\begin{tabular}{|c|c|c|c|}
\hline Symptoms & Signs & Test & Differential diagnosis \\
\hline $\begin{array}{l}\text { Fever, night } \\
\text { sweats, general } \\
\text { malaise }\end{array}$ & $\begin{array}{l}\text { Weight loss, } \\
\text { lymphadenopathy }\end{array}$ & $\begin{array}{l}\text { FBC, LFT, HIV antigen/antibody test, } \\
\text { hepatitis A, B and C antibody, PCR, blood } \\
\text { film, CRP, Paul Burnell EBV, CMV, HSV }\end{array}$ & $\begin{array}{l}\text { Acute infectious cause, depending on history, acute } \\
\text { hepatitis A, B and C, CMV, EBV, tuberculosis, malaria } \\
\text { glandular fever, lymphoma, leukaemia, malignancy }\end{array}$ \\
\hline Diarrhoea & Weight loss & $\begin{array}{l}\text { Stool MCS and OCP; infection screen as } \\
\text { above; colonoscopy and biopsy if persistent }\end{array}$ & Infectious diarrhoea inflammatory bowel disease \\
\hline Rash & & STS, measles, rubella & Syphilis, measles, rubella, VZV *(depending on rash) \\
\hline
\end{tabular}


Fig 1. Tests that diagnose PHI in the absence of detectable antibody.

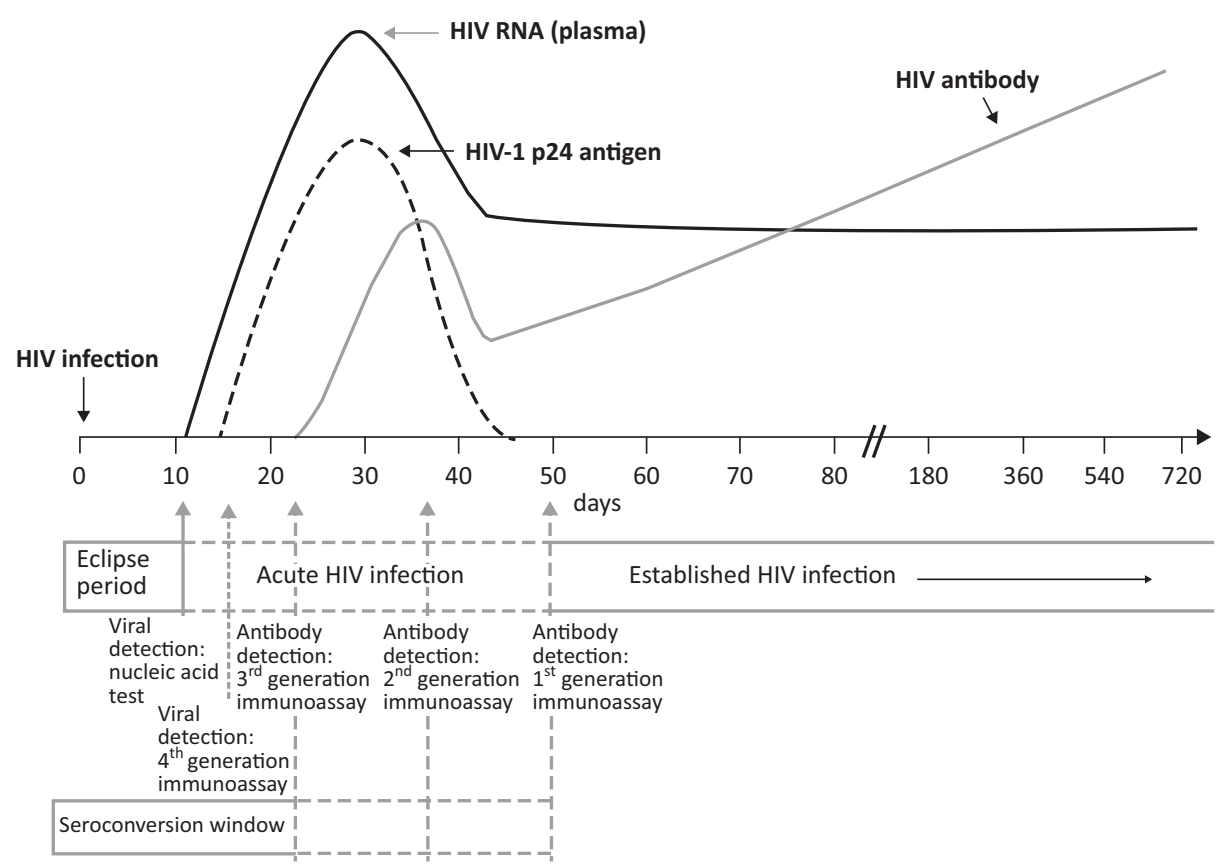

viral remission on stopping ARV, so called functional cure. $^{34,36}$

$>$ All of these benefits are observed the closer to PHI that ART is initiated, particularly in the first 12 weeks. ${ }^{21,32,37,40}$

\section{Duration of ART at PHI}

Three randomised controlled trials in PHI reported a modest benefit (delaying the decline in CD4 cell count, or time from $\mathrm{PHI}$, to requiring lifelong ART) following a 48 -week $^{38}$ or 60 -week ${ }^{39,40}$ course of ART. Interruption of therapy even if started close to the time of PHI is no longer recommended. ${ }^{21}$ Therefore, once started, ART should be taken lifelong.

\section{ART regimen and PHI}

ART regimen should be prescribed in accordance with BHIVA guidelines ${ }^{22}$ which is a three-drug regime; comprising a backbone of two nucleoside reverse transcriptase inhibitors and a third agent from a different class. At PHI whilst any currently approved antiretroviral combination can be commenced in PHI, preference for regimens including integrase inhibitor agents which have been shown to rapidly control viral replication should be considered especially among individuals with extremely high plasma viral load. There are no clinical, immunological or virological data supporting the initiation of more than three drug combinations. The most important factor is expedited ART initiation and good adherence. From UK observational cohort studies there is no evidence of increased rates of drug-related toxicities among individuals treated with high CD4 counts and no increased risk of development of drug resistance among individuals starting early compared with later. Viral suppression should be anticipated by 24 weeks on therapy for the majority of individuals adhering to ART. The time period between ART initiation and viral suppression remains an important risk for onward transmission and must be clearly explained.

\section{Prevention of HIV transmission}

The very high plasma viraemia, often compounded by high rates of concomitant STI and continued high-risk sexual practices among individuals who are unaware of their changed HIV status, makes the short period of PHI highly infectious. Phylogenetic studies among MSM in Brighton and other cities showed that individuals with PHI contributed over $40 \%$ of all new infections. ${ }^{31,32}$ Indeed mathematical models suggest that PHI could be responsible for over half of all new HIV infections in focused epidemics such as the UK. ${ }^{7}$ The use of ART in HIVpositive individuals is the most effective tool to prevent onward viral transmission among HIV serodifferent heterosexual and MSM couples. Recent PEP guidelines advise six months virological suppression before the infection transmission risk is too low to justify PEP provision. ${ }^{41}$ At a population level, the critical barrier to prevention remains diagnosis.

\section{Summary}

Awareness of PHI among certain core high-risk groups, in particular MSM, in the UK is critical to avoid missed diagnoses which impact on individual care and the prevention of onward HIV transmission. Using increased and varied testing, and improving clinician and patient education to recognise symptoms of PHI, will improve PHI diagnosis. Prompt discussion about the benefits of initiating ART at HIV seroconversion (irrespective of CD4 count and viral load) should cover improved surrogate markers of disease progression and a marked reduction in risk of onward viral transmission. Rapid diagnosis followed by immediate risk reduction interventions, screening and treatment of concomitant STIs, and the early initiation of ART to reduce viral load are critical goals to better control the HIV epidemic.

Clinicians should be able to recognise the signs and symptoms of PHI, be confident to offer the appropriate HIV tests and be familiar with local pathways for prompt referral to specialist services. 


\section{References}

1 Public Health England. HIV: surveillance, data and management. London: PHE, 2014. Available online at www.gov.uk/government/ collections/hiv-surveillance-data-and-management [Accessed 10 February 2016].

2 Cohen MS, Chen YQ, McCauley M et al. Prevention of HIV-1 infection with early antiretroviral therapy. N Engl J Med 2011;365:493-505.

3 Cohen M, Chen Y, McCauley M et al. Final results of the HPTN 052 randomized controlled trial: antiretroviral therapy prevents HIV transmission. IAS 2015. 8th Conference on HIV Pathogenesis, Treatment and Prevention [Abstract]. Vancouver: July 19-22, 2015.

4 Rodger A et al. HIV transmission risk through condomless sex if HIV+ partner on suppressive ART: PARTNER study (abstract 153LB). Boston, MA: 21st Conference on Retroviruses and Opportunistic Infections, 2014

5 Quinn TC, Wawer MJ, Sewankambo N et al. Viral load and heterosexual transmission of human immunodeficiency virus type 1 . Rakai Project Study Group. N Engl J Med 2000:30;342:921-9.

6 Ward H, Rönn M. Contribution of sexually transmitted infections to the sexual transmission of HIV. Curr Opin HIV AIDS 2010;5:305-10.

7 Phillips AN, Cambiano V, Miners A et al. Potential impact on HIV incidence of higher HIV testing rates and earlier antiretroviral therapy initiation in MSM. AIDS 2015;29:1855-62.

8 Cohen MS, Shaw GM, McMichael AJ, Haynes BF. Acute HIV-1 Infection. N Engl J Med 2011;364:1943-54.

9 Lodi S, Phillips A, Touloumi G et al. CASCADE Collaboration in EuroCoord. Time from human immunodeficiency virus seroconversion to reaching CD4+ cell count thresholds $<200,<350$, and $<500$ cells/mm3: assessment of need following changes in treatment guidelines. Clin Infect Dis 2011;53:817-25.

10 Katlama C, Deeks SG, Autran B et al. Barriers to a cure for HIV: new ways to target and eradicate HIV-1 reservoirs. Lancet 2013;381:2109-17.

11 Kulpa DA, Chomont N. HIV persistence in the setting of antiretroviral therapy: when, where and how does HIV hide? J Virus Erad 2015;1:59-66.

12 World Health Organization. Service delivery approaches to HIV testing and counseling (HTC): a strategic HTC policy framework. Geneva, Switzerland: WHO, 2012.

13 Westreich DJ, Hudgens MG, Fiscus SA, Pilcher CD. Optimizing screening for acute human immunodeficiency virus infection with pooled nucleic acid amplification tests. J Clin Microbiol 2008;46:1785-92.

14 Centers for Disease Control and Prevention. Laboratory testing for the diagnosis of HIV infection - updated recommendations. Atlanta, GA: CDC, 2014. Available online at www.cdc.gov/hiv/pdf/hivtestingalgorithmrecommendation-final.pdf [Accessed 10 February 2016].

15 Aghaizu A, Murphy G, Tosswill J et al. Recent infection testing algorithm (RITA) applied to new HIV diagnoses in England, Wales and Northern Ireland, 2009 to 2011. Euro Surveill 2014;19:20673.

16 Rosenberg NE, Pilcher CD, Busch MP, Cohen MS. How can we better identify early HIV infections? Curr Opin HIV AIDS 2015;10:61-8.

17 Joore IK, Arts DL, Kruijer MJ et al. HIV indicator condition-guided testing to reduce the number of undiagnosed patients and prevent late presentation in a high-prevalence area: a case-control study in primary care. Sex Transm Infect 2015;91:467-72.

18 Wood M, Ellks R, Grobicki M. Outreach sexual infection screening and postal tests in men who have sex with men: are they comparable to clinic screening? Int J STD AIDS 2015;26:428-31.

19 NHS Choices. Home HIV testing kits now legal in UK. NHS Choices, 10 April 2014. Available online at www.nhs.uk/ news/2014/04April/Pages/Home-HIV-testing-kits-now-legalin-UK.aspx [Accessed 10 February 2016].

20 Krakower DS, Jain S, Mayer KH. Antiretrovirals for primary HIV prevention: the current status of pre- and post-exposure prophylaxis. Curr HIV/AIDS Rep 2015;12:127-38.

21 Rutstein SE, Sellers CJ, Ananworanich J, Cohen MS. The HIV treatment cascade in acutely infected people: informing global guidelines. Curr Opin HIV AIDS 2015;10:395-402.
22 British HIV Association. BHIVA guidelines for the treatment of HIV1-positive adults with antiretroviral therapy 2015. London: BHIVA, 2015. Available online at www.bhiva.org/documents/Guidelines/ Treatment/2015/2015-treatment-guidelines.pdf [Accessed 10 February 2016].

23 INSIGHT START Study Group; Lundgren JD, Babiker AG, Gordin $\mathrm{F}$ et al. A trial of early antiretrovirals and isoniazid preventive therapy in Africa. N Engl J Med 2015;373:808-22.

24 Macatangay BJ, Rinaldo CR. Preserving HIV-specific T cell responses: does timing of antiretroviral therapy help? Curr Opin HIV AIDS 2015;10:55-60.

25 Thornhill J, Inshaw J, Oomeer S et al. Enhanced normalisation of CD4/CD8 ratio with early antiretroviral therapy in primary HIV infection. J Int AIDS Soc 2014;17(4 Suppl 3):19480.

26 Powers KA, Ghani AC, Miller WC et al. The role of acute and early HIV infection in the spread of HIV and implications for transmission prevention strategies in Lilongwe, Malawi: a modelling study. Lancet 2011;378:256-268.87.

27 Miller WC, Rosenberg NE, Rutstein SE, Powers KA. Role of acute and early HIV infection in the sexual transmission of HIV. Curr Opin HIV AIDS 2010;5:277-282.

28 Pinkerton SD. Probability of HIV transmission during acute infection in Rakai, Uganda. AIDS Behav 2008;12:677-84.

29 Hollingsworth T, Anderson R, Fraser C. HIV-1 transmission, by stage of infection. J Infect Dis 2008;198:687-93.

30 Pao D, Fisher M, Hué S et al. Transmission of HIV-1 during primary infection: relationship to sexual risk and sexually transmitted infections. AIDS 2005;19:85-90.

31 Fisher M, Pao D, Brown AE et al. Determinants of HIV-1 transmission in men who have sex with men: a combined clinical, epidemiological and phylogenetic approach. AIDS 2010;24:1739-47.

32 Ananworanich J, Dubé K, Chomont N. How does the timing of antiretroviral therapy initiation in acute infection affect HIV reservoirs? Curr Opin HIV AIDS 2015;10:18-28.

33 Ananworanich J, Dubé K, Chomont N. How does the timing of antiretroviral therapy initiation in acute infection affect HIV reservoirs? Curr Opin HIV AIDS 2015;10:18-28.

34 Williams JP, Hurst J, Stöhr W et al. HIV-1 DNA predicts disease progression and post-treatment virological control. Elife. 2014 Sep 12;3:e03821.

35 Sáez-Cirión A, Bacchus C, Hocqueloux L et al. Post-treatment HIV-1 controllers with a long-term virological remission after the interruption of early initiated antiretroviral therapy ANRS VISCONTI Study. PLoS Pathog 2013;9:e1003211.

36 Fidler S, Porter K, Ewings F et al. Short-course antiretroviral therapy in primary HIV infection. N Engl J Med 2013;368:207-17.

37 Ananworanich J, Sacdalan CP, Pinyakorn S et al. Virological and immunological characteristics of HIV-infected individuals at the earliest stage of infection. J Virus Erad 2016;2:43-8.

38 Hogan C, DeGruttola V, Sun X et al. The SETPOINT study (ACTG A5127): effect of immediate versus deferred antiretroviral therapy on virologic set point in recently HIV-1-infected individuals. J Infect Dis 2012;205:87-96.

39 Grijsen ML, Steingrover R, Wit FW et al. No treatment versus 24 or 60 weeks of antiretroviral treatment during primary HIV infection: The randomised Primo SHM trial. PLoS Med 2012;9: 1001196.

40 Le T, Wright EJ, Smith DM et al. Enhanced CD4+ T-cell recovery with earlier HIV-1 antiretroviral therapy. N Engl J Med 2013;368:218-30.

41 British Association for Sexual Health and HIV. UK guideline for the use of HIV post-exposure prophylaxis following sexual exposure (PEPSE). Macclesfield: BASHH, 2015. Available online at www.bashh.org/documents/HIV\%20PEPSE\%202015\%20 Consultation\%20Doc.pdf [Accessed 9 March 2016]. 